\title{
Malar Rash
}

National Cancer Institute

\section{Source}

National Cancer Institute. Malar Rash. NCI Thesaurus. Code C117106.

An erythematous eruption on the central face, which can be caused by a variety of different conditions. 